\title{
Facebook Intervention for Young-Onset Melanoma Patients and Their Family Members: Pilot and Feasibility Study
}

Elliot J Coups ${ }^{1,2}, \mathrm{PhD}$; Sharon L Manne ${ }^{1,2}$, PhD; Sherry L Pagoto ${ }^{3}$, PhD; Kevin R Criswell ${ }^{1}$, PhD; James S Goydos ${ }^{1,4}$, MD

\footnotetext{
${ }^{1}$ Rutgers Cancer Institute of New Jersey, Rutgers, The State University of New Jersey, New Brunswick, NJ, United States

${ }^{2}$ Department of Medicine, Rutgers Robert Wood Johnson Medical School, Rutgers, The State University of New Jersey, New Brunswick, NJ, United States

${ }^{3}$ Department of Allied Health Sciences, College of Agriculture, Health and Natural Resources, University of Connecticut, Storrs, CT, United States

${ }^{4}$ Department of Surgery, Rutgers Robert Wood Johnson Medical School, Rutgers, The State University of New Jersey, New Brunswick, NJ, United States
}

\section{Corresponding Author:}

Elliot J Coups, PhD

Rutgers Cancer Institute of New Jersey

Rutgers, The State University of New Jersey

195 Little Albany Street

New Brunswick, NJ, 08903

United States

Phone: 17322358076

Fax: 17322358808

Email: coupsej@cinj.rutgers.edu

\begin{abstract}
Background: Despite their elevated melanoma risk, young-onset melanoma patients and their families exhibit low rates of engagement in skin cancer surveillance and sun protection behaviors. Interventions that improve skin cancer surveillance (total cutaneous exam [TCE] and skin self-exam [SSE]) and prevention (sun protection) practices among young-onset patients and their family members would likely have an impact on skin cancer morbidity and mortality; however, such interventions are lacking.

Objective: The objective of our study was to examine the development, feasibility, and preliminary impact of a family-focused Facebook intervention to increase engagement in TCE, SSE, and sun protection among young-onset melanoma patients and their families.

Methods: In this study, 48 young-onset melanoma patients and their 40 family members completed measures of knowledge; beliefs; and TCE, SSE, and sun protection intentions before and 1 month after participating in 1 of 5 separate "secret" (ie, private) Facebook groups. The intervention content consisted of daily postings about skin cancer, skin cancer risk factors, TCE, SSE, and sun protection.

Results: Patient and family member participation rates differed by recruitment setting, with acceptance rates ranging from $24.6 \%$ to $39.0 \%$ among families recruited from a cancer center setting and from $12.7 \%$ to $61.5 \%$ among families recruited from a state registry. Among the 5 consecutive groups conducted, engagement, as measured by comments and likes in response to postings, increased across the groups. In addition, participants positively evaluated the intervention content and approach. Preliminary analyses indicated increases in TCE, SSE, and sun protection intentions.

Conclusions: Our family-focused Facebook intervention showed promise as a potentially feasible and efficacious method to increase sun protection and skin cancer surveillance among individuals at increased risk for melanoma.
\end{abstract}

(JMIR Dermatol 2018;1(2):e3) doi: 10.2196/derma.9734

\section{KEYWORDS}

young adults with melanoma; family interventions; sun protection; skin surveillance; skin examination; social media; Facebook 


\section{Introduction}

The incidence of young-onset melanoma, defined as a diagnosis of melanoma before the age of 40 , is increasing; the risk of developing melanoma is more than 6 times higher among young adults than it was 40 years ago [1]. Melanoma is the most common malignancy occurring among young adults aged 25-29 years and the second most common malignancy among persons aged 15-29 years [2]. Having a first-degree relative with melanoma more than doubles a person's melanoma risk, which can be attributed to genetics as well as shared environmental factors [3]. Furthermore, spouses or partners of melanoma patients are at increased risk for melanoma [4], which may be due to shared environmental or phenotypic risk factors. Thus, the population of family members at an elevated risk for melanoma is growing in tandem with the increase in the patient population.

Melanoma risk is known to be associated with the magnitude of ultraviolet radiation exposure [5-7]. The American Cancer Society and other agencies (eg, Skin Cancer Foundation) recommend prevention by avoiding exposure to ultraviolet light during peak exposure hours and recommend using sunscreen and sun-protective clothing. The American Cancer Society also recommends regular surveillance for adults, including total cutaneous exams (TCEs) by a health care provider and comprehensive skin self-exams (SSEs). TCE is a cost-effective and safe procedure that facilitates the identification of thinner lesions that can be treated more successfully than thicker ones $[8,9]$. Comprehensive SSE confers up to a $63 \%$ reduction in melanoma risk [10]. Reportedly, $40 \%-45 \%$ of diagnosed melanomas are initially detected by patients incidentally or while conducting a deliberate SSE [11]. Adherence to TCE and SSE is likely to reduce the cancer burden as well as the incidence of malignant melanomas diagnosed at advanced stages, particularly among populations at an elevated risk.

The US Preventive Services Task Force states that there is insufficient evidence to recommend regular TCE and SSE for the general population of average-risk adults. However, professional and preventive services groups recommend routine screening for higher-risk persons who have an first-degree relative with melanoma $[2,12]$. It is recommended that these at-risk family members should engage in regular sun protection and undergo routine TCEs and SSEs [2,12].

Despite their elevated melanoma risk, engagement in TCE, SSE, and sun protection is low among first-degree relatives of melanoma patients. Between $47 \%$ and $59 \%$ of first-degree relatives report ever having a TCE [13-15], and about one-third of first-degree relatives have not conducted an SSE in the past year [10,14-16]. Reportedly, engagement in regular sun protection ranges from $20 \%$ to $59 \%$ [13-15]. The limited work conducted to date has indicated that engagement in TCE, SSE, and sun protection is similarly low among first-degree relatives of young-onset melanoma patients (Manne, unpublished data).

Moreover, young-onset melanoma survivors are at a higher relative risk for a second malignancy than adults diagnosed with cancer who are over 39 years of age [17]. The cumulative incidence of secondary malignancies rises faster over time for young adult survivors than for childhood and older adult survivors [17]. Follow-up guidelines for melanoma patients recommend that they reduce their risk for secondary malignancies by receiving a periodic TCE, conducting a regular SSE, and engaging in regular sun avoidance and protection $[18,19]$. Although most melanoma patients receive a periodic TCE [20-22], only 14\%-39\% of patients conduct a thorough SSE on a regular basis $[8,9,23,24]$. Prior research has indicated that engagement in recommended TCE is very high among young-onset melanoma patients (Manne, unpublished). Only $59 \%$ of young-onset melanoma patients have reported engaging in SSE in the past year (Manne, unpublished). Even among those reporting a skin exam, comprehensiveness of self-exams is low (eg, $42 \%$ examine their feet, $29 \%$ examine their scalp; Manne, unpublished). Furthermore, engagement in regular sun protection is low (Manne, unpublished).

Young-onset melanoma patients and their family members are a growing and unique cancer population who are at elevated skin cancer risk. Effective interventions to improve their surveillance and prevention practices will likely have an impact on skin cancer morbidity and mortality. Prior behavioral interventions for melanoma patients and their family members have primarily been delivered in person or via individual print or telephone counseling [25,26]. Few of these interventions have targeted both patients and their family members. For example, Bowen et al [27] found that a Web-based family communication intervention improved skin surveillance and sun protection behaviors among melanoma patients and their family members compared with that among a wait-list control group. In another study, melanoma patients and their family members reported greater engagement in SSE behaviors after receiving a dyadic compared with a solo learning intervention [28].

An intervention that is delivered via a social media modality offers some advantages over other intervention modalities. One advantage is the high reach. Young adults are high users of Facebook [29]. Second, social media platforms allow users to interact with one another and create their own content. Closed social media platforms such as secret Facebook groups allow for the formation of a group environment where patients can engage with other patients who have undergone similar experiences, family members can interact with the families of other patients, and everyone can view all postings. This engagement may facilitate group support for behavior change and promote the setting of social norms and expectations for practices and attitudes. Normative influences drive attitudinal change and play a role in sun protection and SSE for individuals at increased risk for melanoma, including individuals with a personal or family history of melanoma $[15,30]$. Third, social media allows health care providers to interact with participants. For example, cutaneous oncologists can address questions about skin cancer that are viewed by all members of the group. Finally, social media modalities provide a less expensive way to disseminate information and skills [31]. Because of these advantages, social media modalities such as Facebook have been incorporated as a component of behavioral interventions to reduce tobacco use [32], improve physical activity [33,34], 
and enhance weight loss [35]. To date, there have been few stand-alone Facebook interventions [36].

This study reports on the development and acceptability of a family-focused Facebook intervention for young-onset melanoma patients and their family members. Young-onset survivors face unique challenges and have unique needs and preferences. They manage survivorship recommendations at a time when they manage other life tasks such as choosing life partners, starting or finishing new educational or occupational pursuits, and starting or caring for their own families [37,38]. In addition, their family members are likely younger than those of patients diagnosed at an older age and, therefore, may face similar challenges in engaging in skin cancer risk-reducing behaviors. This study had two aims. The first aim was to evaluate the feasibility of the intervention, which was measured by recruitment rates, participation in the Facebook groups, retention, and acceptability. The second aim was to provide a preliminary examination of the impact of the intervention on knowledge; beliefs (family perceptions and support, sun protection benefits and barriers, SSE benefits and barriers, and norms); and sun protection, SSE, and TCE intentions.

\section{Methods}

\section{Procedure}

Patients were recruited from the Rutgers Cancer Institute of New Jersey (CINJ) and via referral from the New Jersey State Cancer Registry (NJSCR). At CINJ, potentially eligible patients were identified by reviewing outpatient medical appointments and electronic medical records. Patients were either approached in the clinic area or sent a letter about the study, along with an informed consent form and postage-paid return envelope. The patients who were sent a letter were telephoned by a member of the research team. For the NJSCR, potentially eligible patients were identified through a case review of pathology reports and other surveillance records. Each patient's treating physician of record was contacted by a staff member from the NJSCR to ensure that the patient could be contacted. Physicians had 2 weeks to respond, after which an NJSCR staff member contacted patients via letters and telephone to obtain permission to share their contact information with the research team at CINJ. Patients who provided permission were mailed a letter about the study, along with the informed consent form and a postage-paid return envelope. They were then contacted via telephone to determine their eligibility and interest in the study. Eligible and interested patients were asked to provide the name and contact information of a spouse or partner and one or more first-degree relatives. These family members were recruited using the same procedures as outlined above for patients. All participants provided informed consent either by completing a hard-copy consent form or electronically using a secure Web-based form.

After providing informed consent, participants completed a Web-based or pencil and paper baseline survey that included questions on demographic factors; Facebook use; and skin cancer-related knowledge, beliefs, and behavioral intentions. Participants were then invited to join a study-specific "secret" Facebook group. A secret group on Facebook can only be viewed by invited individuals, and the name and existence of the group are not publicly disclosed on Facebook. Furthermore, posts to secret Facebook groups cannot be shared on Facebook outside of the group members.

\section{Participants}

Participants were melanoma patients and their family members (ie, spouses or partners, siblings, parents, and children). The eligibility criteria for patients were as follows: those diagnosed with melanoma within the past 5 years; diagnosed with stage 0-III melanoma between the ages of 18 and 45 years; not currently on active treatment for melanoma or any others cancer; able to speak and read English; with access to a computer with internet access and familiarity with social media platforms; with a spouse, partner, or first-degree relative(s) eligible and willing to participate in the study; and able to give meaningful informed consent. For family members, the eligibility criteria were as follows: those aged 18-89 years; able to speak and read English; with access to a computer with internet access and familiarity with social media platforms; and able to give meaningful informed consent.

\section{Survey Measures}

A copy of the survey is available in Multimedia Appendix 1.

\section{Demographics and Facebook Use (Assessed at Baseline Only)}

Participants reported their sex, age, and highest level of education. They also indicated the number of Facebook friends they have and the amount of time per day they spend on Facebook.

\section{Knowledge and Beliefs (Assessed at Baseline and Follow-Up)}

Knowledge about skin cancer risk factors was assessed using 13 true or false items drawn from prior research [15]. A total knowledge score was obtained by summing the number of correct responses for each participant. Family perceptions about skin cancer risk, sun protection, and SSE [15,39] is a 9-item measure assessing perceived benefits of sun protection and SSE to one's family as well as discussions with family about these topics (Cronbach alpha=.92 and .94 for the baseline and follow-up surveys, respectively). The family support measure was developed for this study; its 4 items measured the degree to which the participants supported their family members engaging in regular sun protection and regular SSE as well as how important it is that their family members engage in these behaviors (Cronbach alpha $=.92$ and .95 , respectively). An 8-item measure assessed the benefits of sun protection (sunscreen, sun-protective clothing; Cronbach alpha=.84 and .82, respectively) [15]. A 15-item measure assessed perceived barriers to using sunscreen (Cronbach alpha $=.87$ and .83 , respectively), and an 11-item measure assessed barriers to wearing sun-protective clothing (Cronbach alpha=.86 and .89 , respectively) [40]. An 8-item measure assessed SSE benefits (Cronbach alpha=.79 and .87, respectively) [15], and an 11-item measure assessed barriers to SSE (Cronbach alpha=.76 and .80 , respectively) [15]. Tanning norms (5 items) measured family and friends' sunbathing practices (Cronbach alpha=.74 and .72, 
respectively). Sun protection norms (7 items) measured family and friends' sun protection practices and attitudes (Cronbach alpha $=.83$ and .71 , respectively). Furthermore, image norms for tanness (5 items) assessed participants' beliefs about societal beliefs regarding the importance of tanned appearance for celebrities and society (Cronbach alpha=.67 and .56, respectively) [41].

\section{Behavioral Intentions (Assessed at Baseline and Follow-Up)}

Sun protection intentions were assessed by averaging responses to 8 items (Cronbach alpha=.85 and .86 at baseline and follow-up, respectively) [42]. SSE intentions were assessed by averaging responses to 2 items (Cronbach alpha $=.98$ and .92 , respectively) [42], and a single item was used to assess TCE intentions [42]. Furthermore, the measure of TCE intentions was only included in the final 2 Facebook groups.

\section{Evaluations of the Facebook Groups (Assessed Immediately After Group Completion)}

Drawing on prior research [42-44] and items developed for this project, 20 items assessed participants' evaluations in each Facebook group. Each item utilized a 7-point response scale. We created 3 subscales: evaluation of the content (7 items, Cronbach alpha $=.92$; eg, "The information I received was interesting"); helped prepare participants to discuss sun protection and exams with one's family (5 items, Cronbach alpha=.97; eg, "After participating in the group and viewing posts, I feel more prepared to talk to my family about engaging in regular sun protection, skin self-exams, and exams by a doctor"); and the overall Facebook experience (8 items, Cronbach alpha=.93; eg, "I felt comfortable participating in the discussions that we had on the Facebook group"). Correlations among the 3 subscales varied from $r=.56$ to $r=.81$. Additionally, we used open-ended questions to solicit additional feedback.

\section{Overview of the Facebook Groups}

We conducted 5 separate secret Facebook groups. After each group, the team met to decide upon changes to be made to content based on the information garnered from debriefing interviews with participants. An overview of the characteristics of the 5 groups is shown in Table 1. For each group, the research team posted approximately two times per day on average (typically morning and late afternoon), including weekends.
The posts focused on the following broad topics: skin cancer risks, sun protection, SSE, and TCE. Additionally, the content of the posts was informed by the Preventive Health Model [45] and the Theory of Normative Social Behavior [46,47]. For example, posts focused on skin cancer knowledge, benefits and barriers to behavior change, goal setting, family support, and normative beliefs. As outlined later, some variation existed in the content and order of posts across the Facebook groups. In general, posts included a small amount of text content, typically accompanied by a photograph or graphic image. Some posts asked participants to respond to a poll, complete a quiz, or provide a viewpoint or answer to a question by commenting on the post. Example Facebook posts are shown in Figure 1 (a welcome message) and Figure 2 (a family support and engagement message).

For all Facebook groups, participants were asked to complete a Web-based, paper and pencil, or telephone Facebook evaluation survey immediately after the end of the group. The evaluation survey was completed by $76 \%$ (67/88) of the participants. In addition, participants were invited to complete a semistructured telephone interview at the end of the group that solicited feedback on study procedures and the content of the Facebook groups. For participants who had previously completed the Facebook evaluation survey, the interview provided them with an opportunity to expand on their survey responses. The number of individuals completing a semistructured interview for each group was as follows: group 1, $\mathrm{n}=4$; group 2, $\mathrm{n}=8$; group 3, $\mathrm{n}=5$; group 4, $\mathrm{n}=19$; group 5, $\mathrm{n}=17$ (overall completion rate $=53 / 88,60 \%$ ). Results of the Facebook evaluation surveys and semistructured interviews were reviewed by research team members and used to inform the content and approach of subsequent groups. Participants in groups 2-5 were asked to complete a follow-up Web-based or pencil and paper survey 1 month after the end of the group that included the questions on skin cancer-related knowledge, beliefs, and behavioral intentions from the baseline survey (overall completion rate $=65 / 80,81 \%$ ). Furthermore, participants received a US $\$ 50$ gift card for completing each of the baseline and follow-up surveys (but did not receive compensation for completing the Facebook evaluation survey or the telephone interview). This study was approved by the Rutgers Health Sciences Institutional Review Board.

Table 1. Characteristics of the Facebook groups.

\begin{tabular}{lllllll}
\hline Group number & Date of group & $\begin{array}{l}\text { Length of } \\
\text { group (days) }\end{array}$ & $\begin{array}{l}\text { Posts (n) } \\
\text { 1 }\end{array}$ & $\begin{array}{l}\text { Patients in } \\
\text { the group (n) }\end{array}$ & $\begin{array}{l}\text { Family members in } \\
\text { the group (n) }\end{array}$ & $\begin{array}{l}\text { Total group } \\
\text { members (N) }\end{array}$ \\
\hline 2 & May 2016 & 15 & 31 & 2 & 6 & 8 \\
3 & July-August 2016 & 28 & 53 & 7 & 4 & 11 \\
4 & November-December 2016 & 29 & 56 & 4 & 6 & 10 \\
5 & January-February 2016 & 28 & 54 & 14 & 10 & 24 \\
\hline
\end{tabular}


Figure 1. Example Facebook post 1. Photograph from Getty Images; credit: andres; creative \#: 489039170; licensed under fair use.

$$
\begin{aligned}
& \text { Hi everyone! Welcome to the Young } \\
& \text { Melanoma Family Facebook Group. This } \\
& \text { group, which will last for one month, is made } \\
& \text { up of } 21 \text { young people who have been } \\
& \text { diagnosed with melanoma as well as } 12 \text { of } \\
& \text { their family members. In this Facebook group, } \\
& \text { we encourage participation in the form of } \\
& \text { comments and "likes" so that we can make } \\
& \text { this a great group experience for everyone! } \\
& \text { Even brief comments ("I agree!" or "I am not } \\
& \text { sure about that...") are encouraged! }
\end{aligned}
$$

Tell us a little about yourself or your family.

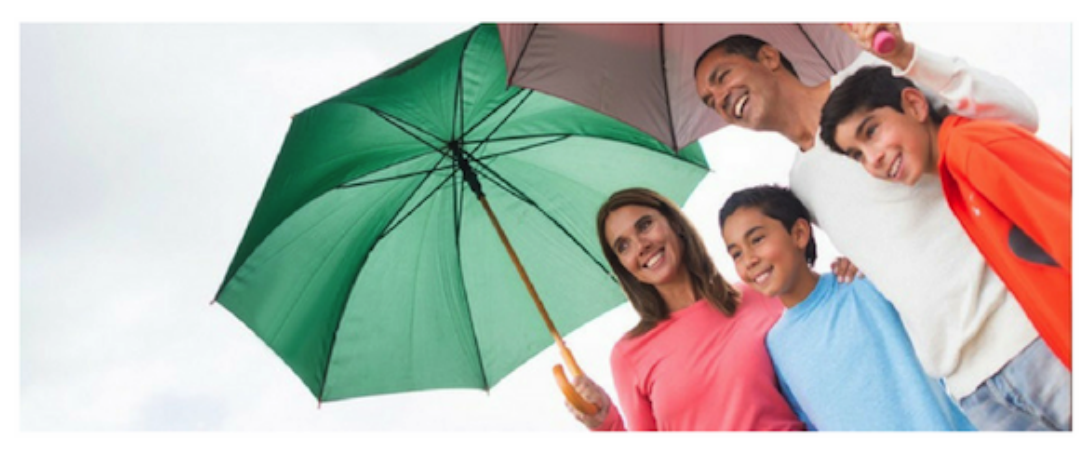

Figure 2. Example Facebook post 2.

We have brothers, sisters, and parents as well as people with skin cancer in this group. I know that families can really help one another with sun protection habits. For example, my mom has had skin cancer, and before we go to the car, I remind her to get her sunglasses.

What ways can you support your family members who are in this group with their sun protection goals?

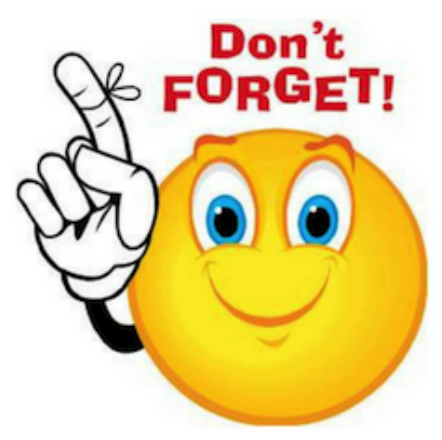




\section{Facebook Group 1}

For this group, participants received a 1-page handout in the mail after completing the baseline survey. As shown in Figure 3 , the handout welcomed individuals to the program, described the goals of the program, and gave brief advice on how to reduce risk for skin cancer. There was no specific order to the Facebook posts, and the moderator only posted content but did not reply or engage in any conversation with participants in the group. The posts focused primarily on skin cancer risks and sun protection, with only 2 messages on SSE and 1 message on TCE. Several posts were memes or links to external sites. Changes suggested by one or more participants included the following: (1) organize messages by weekly topics; (2) increase the duration of the group to provide more content; (3) increase interactivity (eg, quizzes); (4) drop memes; and (5) use personal narratives.

\section{Facebook Group 2}

For this group, participants again received a 1-page handout in the mail after completing the baseline survey; we extended the length of the group to 28 days and included moderator's comments on most posts. Additionally, we grouped the posts into weekly topics: week 1 , skin cancer risks; week 2 , sun protection; week 3, SSE; and week 4, TCE. The posts included quizzes, personal narratives, polls, tailored information about the group's beliefs and behaviors (based on data from the baseline survey), and also addressed family influences. Several "ask the doctor" posts with prepared questions and answers were posted on behalf of a medical oncologist. Changes suggested by one or more participants included the following: (1) include information on planning behavior change; (2) provide alternate ways to consider barriers; (3) include more information on benefits; (4) include more pictures with posts; (5) reduce the length of posts; (6) add more discussion questions, and; (7) include more interaction with a medical oncologist.

\section{Facebook Group 3}

For this group and the subsequent groups, we removed the mailed 1-page handout. Posts for Facebook group 3 were revised to address the changes suggested by group 2 participants. For example, posts encouraged participants to develop behavior change goals and to identify potential barriers and solutions. In addition, a medical oncologist joined the group and answered questions on a more regular basis. Furthermore, more posts were made by moderators, and they encouraged group participation. Changes suggested by one or more participants included the following: (1) have larger groups to promote group interaction; (2) include more information about the dangers of indoor tanning; (3) increase the number of posts targeting young adults; and (4) include recent news or research about skin cancer.

Figure 3. Handout mailed to participants in Facebook groups 1 and 2.

\section{Welcome to the Melanoma Family Program}

The Melanoma Family Program is a
research study focusing on individuals
and families affected by melanoma skin
cancer.
You were asked to take part in this
study because you have been
diagnosed with melanoma skin cancer
or you have a family history of
melanoma skin cancer. Your personal
or family history of melanoma makes
you at higher risk for skin cancer than
the general population.
Before we get started, we wanted to
share a personal melanoma story.
"My mother was diagnosed
with melanoma skin
cancer three years ago At
that time, I wasn't aware
that I was at risk for the
disease. Since that time, I
have seen a dermatologist
every year to have her
examine my skin. I feel
reassured after I see her."

The Melanoma Family Program is a research study focusing on individuals and families affected by melanoma skin diagnosed with melanoma skin cancer or you have a family history of melanoma skin cancer. Your personal or family history of melanoma makes you at higher risk for skin cancer than Before we get started, we wanted to share a personal melanoma story.

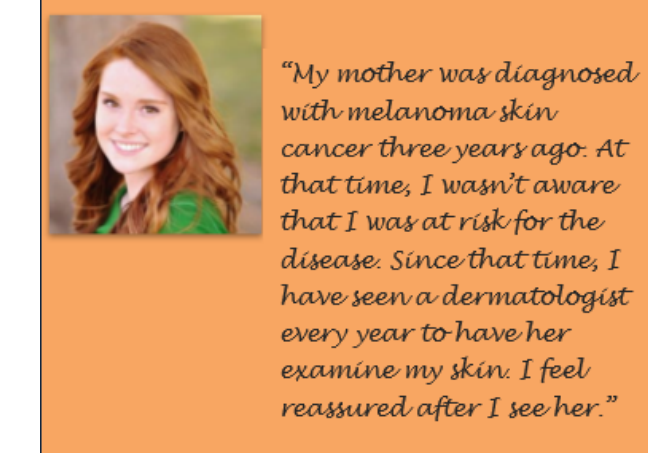

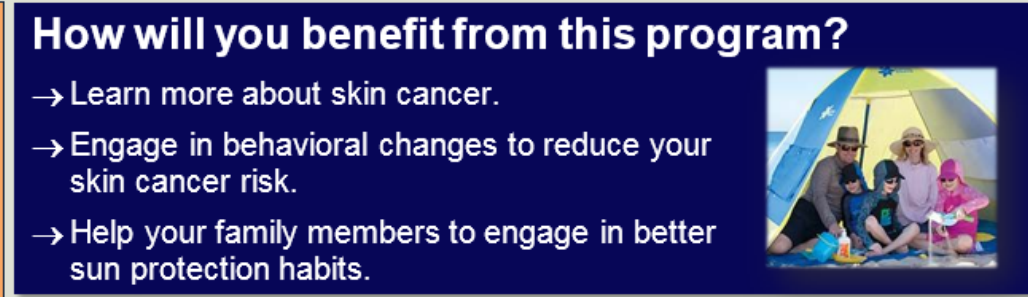

\section{What will you get out of this program?}

Receive several information sheets emailed to you over the next two weeks containing important facts about melanoma skin cancer and ways to reduce your and your family members' risk.

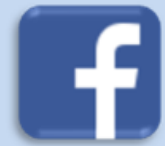

Be a member of the Secret Family Facebook Group where you will join members of your family and other families affected by melanoma to share your experiences and learn more about skin cancer risk reduction.

How can you reduce your risk for skin cancer?

$\checkmark$ Minimize your exposure to direct sunlight between the hours of $10 \mathrm{a} . \mathrm{m}$. and 4 p.m.

$\checkmark$ Examine your own skin regularly and see a dermatologist if you find something suspicious.

$\checkmark$ Have a dermatologist examine your skin for signs of skin cancer every year or more frequently if that is recommended for you. 


\section{Facebook Group 4}

The primary change for this group was to increase the number of group members to 24. Additionally, posts were revised to focus more on indoor tanning, young adults, and skin cancer-related news and research. Participants provided positive feedback about the group, with the primary suggestion being to have an even larger group.

\section{Facebook Group 5}

This group utilized the same posts and approach for group 4 but with a larger group of 35 individuals. Again, participants were enthusiastic about the group, suggested more encouragement of group support, and suggested a larger group size.

\section{Results}

\section{Sample Characteristics}

As detailed below, a total of 88 individuals (48 melanoma patients and 40 family members) participated across 5 separate Facebook groups. The demographic characteristics of the study sample are shown in Table 2 . Among the 40 family members, 8 were the spouse or partner of the patient, 1 was the child, 19 were the sibling, and 12 were the parents. Among both patients and family members, the proportion of female participants was markedly higher than that of male participants. In part, this may be due to the higher rate of melanoma among young adult women than among men. The sample exhibited a relatively high level of education, with more than three-quarters of participants $(71 / 88,81 \%)$ reporting completing college or a graduate degree. Patients reported having a greater number of Facebook friends than their family members $(P=.01)$, but the 2 groups did not differ with regard to the amount of time per week spent on Facebook $(P=.81)$.

\section{Acceptability}

\section{Enrollment}

At CINJ, a total of 64 patients were approached for the study. Of them, 7 were ineligible and 40 declined to participate (either actively or passively); 17 patients consented and completed the baseline survey (consent rate $=17 / 57,30 \%$ ) and 14 joined a Facebook group (overall Facebook joining rate=14/57, 25\%). The 17 recruited patients provided contact information for a total of 44 spouses or partners and first-degree relatives. Of those 44 individuals, 3 were ineligible, 23 declined participation, 18 consented and completed the baseline survey (consent rate $=18 / 41,44 \%$ ), and 16 joined a Facebook group (overall Facebook joining rate $=16 / 41,39 \%$ ).

The staff of the NJSCR approached 292 patients regarding the study, 23 of whom were ineligible and 203 declined to provide permission to be contacted by the CINJ research team. Among 66 patients who gave permission to be contacted by the CINJ research team, 2 patients were ineligible, 27 declined to participate, 37 completed Web-based consent and the baseline survey (consent rate $=37 / 267,13.9 \%$ ), and 34 joined a Facebook group (overall Facebook joining rate=34/267, 12.7\%). The 37 recruited patients provided contact information for a total of 40 spouses or partners and first-degree relatives. Of those 40 individuals, 1 was ineligible, 11 declined participation, 28 completed Web-based consent and the baseline survey (consent rate $=28 / 39,72 \%$ ), and 24 joined a Facebook group (overall Facebook joining rate $=24 / 39,62 \%$ ).

\section{Retention}

Completion of the follow-up survey varied from $60 \%$ (6/10 for group 3) to $85 \%$ (50/59 for groups 4 and 5 combined).

\section{Engagement}

The engagement characteristics of the Facebook groups are shown in Multimedia Appendix 2. On average, participants viewed $66 \%-83 \%$ of posts. The average number of likes and comments per post was higher for groups 4 and 5, even after taking into account the higher number of participants in those groups and higher number of moderator posts in the latter groups. Furthermore, Multimedia Appendix 2 illustrates that the percentage of participants who liked and commented on $25 \%$ of the posts increased over the 5 subsequent groups. As outlined earlier, we increased the number of posts across each subsequent Facebook group.

\section{Evaluation}

The descriptive statistics for participants' evaluations of each Facebook group are shown in Table 3. Mean ratings of the intervention content in Facebook group 1 were relatively low compared with those in the subsequent groups. In groups 2-5, there were positive evaluations across the evaluation subscales, particularly with regard to the intervention content and feeling more prepared to discuss relevant issues with family members.

Comments made during the debriefing interview included input about the delivery method ("Facebook is a good medium for what you are doing"), content that was well liked ("I liked the Ask the Expert posts," "I liked the Mole Map," "I liked when we shared our personal stories"), impact on behavior ("I enjoyed information about sunscreen. I never used it before, and now I am more conscious," "I am going to see a dermatologist," "I need to ask my doctor to do a more thorough exam of my skin"), and how the material impacted discussions with family (eg, "I shared the posts with my children," "My mom talked to me about the posts"). Some participants commented that they wished there be more group discussion.

\section{Changes in Outcomes From the Baseline to the Follow-Up}

Changes in the outcomes from the baseline to the follow-up are shown in Table 4, which includes mean changes and their respective $95 \%$ CIs. Owing to the small sample sizes, we did not conduct formal inferential statistics. We provided CIs to provide a preliminary indication of potential effects. We conducted analyses separately for groups 2 and 3 due to the substantive differences between the messages and approach utilized in these groups. We analyzed results combined for groups 4 and 5 due to the strong similarity between their messages, approach, and sample sizes and to reduce the CI widths. There was some indication that knowledge scores improved across some groups, as did family perceptions and sun protection benefits. Counter to expectations, barriers to using sunscreen and sun-protective clothing were higher in 
several groups at follow-up compared with those at baseline. There was some indication that SSE benefits increased over time, but evidence was inconsistent with regard to changes in SSE barriers. Moreover, results were inconsistent with regard to changes in norms across the groups. Encouragingly, the most consistent beneficial effects were observed for behavioral intentions, particularly with regard to groups 4 and 5. For these groups, each of the CIs excluded zero and indicated increases in sun protection, SSE, and TCE intentions from baseline to follow-up.

Table 2. Demographic characteristics of the study sample ( $\mathrm{N}=88)$.

\begin{tabular}{|c|c|c|}
\hline Chacteristic & Patients $(n=48)$ & Family members $(n=40)$ \\
\hline \multicolumn{3}{|l|}{ Recruitment site, $\mathbf{n}(\%)$} \\
\hline Rutgers Cancer Institute of New Jersey & $14(29)$ & $16(40)$ \\
\hline New Jersey State Cancer Registry & $34(71)$ & $24(60)$ \\
\hline \multicolumn{3}{|l|}{ Relation to patient, $\mathrm{n}(\%)$} \\
\hline Spouse or partner & $-^{\mathrm{a}}$ & $8(20)$ \\
\hline Daughter & - & $1(3)$ \\
\hline Son & - & $0(0)$ \\
\hline Sister & - & $12(30)$ \\
\hline Brother & - & $7(18)$ \\
\hline Mother & - & $8(20)$ \\
\hline Father & - & $4(10)$ \\
\hline \multicolumn{3}{|l|}{ Sex, n (\%) } \\
\hline Female & $42(88)$ & $26(65)$ \\
\hline Male & $6(13)$ & $14(35)$ \\
\hline Age (years), mean (SD) & $34.5(6.4)$ & $39.5(13.2)$ \\
\hline $18-25, \mathrm{n}(\%)$ & $7(15)$ & $7(18)$ \\
\hline $26-35, \mathrm{n}(\%)$ & $17(35)$ & $10(25)$ \\
\hline $36-45, \mathrm{n}(\%)$ & $24(50)$ & $8(20)$ \\
\hline $46-55, \mathrm{n}(\%)$ & $0(0)$ & $8(20)$ \\
\hline$\geq 56, \mathrm{n}(\%)$ & $0(0)$ & $7(18)$ \\
\hline \multicolumn{3}{|l|}{ Education level, n (\%) } \\
\hline$\leq$ High school or General Educational Development & $5(10)$ & $4(10)$ \\
\hline Some college & $3(6)$ & $5(13)$ \\
\hline College graduate & $27(56)$ & $19(48)$ \\
\hline Graduate degree & $13(27)$ & $12(30)$ \\
\hline \multicolumn{3}{|l|}{ Number of Facebook friends, $n(\%)$} \\
\hline$\leq 100$ & $5(11)$ & $15(40)$ \\
\hline $101-200$ & $7(15)$ & $5(13)$ \\
\hline 201-300 & $12(26)$ & $4(11)$ \\
\hline $301-400$ & $8(17)$ & $14(37)$ \\
\hline$>400$ & $15(32)$ & $0(0)$ \\
\hline \multicolumn{3}{|l|}{ Minutes per day of Facebook use, $n(\%)$} \\
\hline$<10$ & $8(17)$ & $5(13)$ \\
\hline $10-60$ & $18(38)$ & $18(47)$ \\
\hline $61-120$ & $10(21)$ & $6(16)$ \\
\hline$>120$ & $11(23)$ & $9(24)$ \\
\hline
\end{tabular}

${ }^{\mathrm{a}}$ Not applicable. 
Table 3. Participants' evaluations of each Facebook group.

\begin{tabular}{lllllll}
\hline Variable $^{\mathrm{a}}$ & $\begin{array}{l}\text { Group 1 (n=6), } \\
\text { mean (SD) }\end{array}$ & $\begin{array}{l}\text { Group 2 (n=9), } \\
\text { mean (SD) }\end{array}$ & $\begin{array}{l}\text { Group 3 }(\mathrm{n}=7), \\
\text { mean (SD) }\end{array}$ & $\begin{array}{l}\text { Group 4 (n=19), } \\
\text { mean (SD) }\end{array}$ & $\begin{array}{l}\text { Group 5 (n=26), } \\
\text { mean (SD) }\end{array}$ & $\begin{array}{l}\text { All groups, } \\
\text { mean (SD) }\end{array}$ \\
\hline $\begin{array}{l}\text { Evaluation of content } \\
\text { Helped prepare me }\end{array}$ & $4.86(1.68)$ & $6.19(1.05)$ & $6.31(0.79)$ & $5.66(1.37)$ & $6.21(0.71)$ & $5.94(1.14)$ \\
Facebook experience & $3.56(1.46)$ & $6.37(1.32)$ & $6.16(1.08)$ & $5.05(1.72)$ & $6.14(0.93)$ & $5.63(1.52)$ \\
Overall, mean (SD) & $-\mathrm{b}$ & - & $5.25(1.16)$ & $5.45(1.55)$ & $5.87(0.99)$ & $5.63(1.25)$ \\
\hline
\end{tabular}

${ }^{a}$ All subscales were scored on a 1-7 scale, with higher numbers reflecting more positive evaluations.

${ }^{\mathrm{b}}$ Subscale questions were not asked of participants in that Facebook group.

Table 4. Mean changes in outcomes from baseline (BL) to follow-up (FU) for the Facebook groups.

\begin{tabular}{|c|c|c|c|c|c|c|c|c|c|}
\hline \multirow[t]{2}{*}{ Outcomes } & \multicolumn{3}{|c|}{ Group $2(n=9)$} & \multicolumn{3}{|c|}{ Group $3(\mathrm{n}=6)$} & \multicolumn{3}{|c|}{ Groups 4 and $5(n=50)$} \\
\hline & $\mathrm{BL}$ & FU & Change $(95 \% \mathrm{CI})$ & $\mathrm{BL}$ & FU & Change $(95 \% \mathrm{CI})$ & $\mathrm{BL}$ & FU & Change $(95 \% \mathrm{CI})$ \\
\hline Knowledge & 11.67 & 11.89 & $0.22(-0.42$ to 0.86$)$ & 11.50 & 12.17 & $0.67(0.12$ to 1.21$)$ & 12.00 & 12.04 & $0.04(-0.27$ to 0.35$)$ \\
\hline Family perceptions & 4.43 & 4.49 & $0.06(-0.19$ to 0.32$)$ & 4.39 & 4.69 & $0.30(-0.28$ to 0.88$)$ & 4.54 & 4.50 & $-0.04(-0.25$ to 0.17$)$ \\
\hline Family support & 4.72 & 4.72 & $0.00(-0.10$ to 0.10$)$ & 4.88 & 4.83 & $-0.04(-0.30$ to 0.22$)$ & 4.79 & 4.74 & $-0.06(-0.24$ to 0.13$)$ \\
\hline Sun protection benefits & 4.63 & 4.38 & $-0.25(-1.03$ to 0.53$)$ & 4.48 & 4.63 & $0.14(-0.72$ to 1.01$)$ & 4.62 & 4.67 & $0.05(-0.04$ to 0.14$)$ \\
\hline Sunscreen barriers & 1.73 & 1.92 & $0.18(-0.26$ to 0.63$)$ & 2.43 & 2.53 & $0.11(-0.48$ to 0.69$)$ & 2.25 & 2.26 & $0.02(-0.16$ to 0.20$)$ \\
\hline Clothing barriers & 2.47 & 2.92 & $0.45(-0.83$ to 1.74$)$ & 2.55 & 2.91 & $0.36(-0.53$ to 1.26$)$ & 3.01 & 2.97 & $-0.04(-0.22$ to 0.14$)$ \\
\hline Sun protection intentions & 5.64 & 5.69 & $0.05(-0.28$ to 0.37$)$ & 5.15 & 5.30 & $0.15(-1.98$ to 2.28$)$ & 4.94 & 5.33 & $0.39(0.17$ to 0.61$)$ \\
\hline $\mathrm{SSE}^{\mathrm{a}}$ benefits & 5.47 & 5.42 & $-0.05(-0.58$ to 0.49$)$ & 5.28 & 5.65 & $0.38(-0.04$ to 0.79$)$ & 5.16 & 5.28 & $0.12(-0.11$ to 0.35$)$ \\
\hline SSE barriers & 3.05 & 3.18 & $0.14(-0.82$ to 1.10$)$ & 3.13 & 3.18 & $0.05(-0.42$ to 0.52$)$ & 2.98 & 2.93 & $-0.06(-0.22$ to 0.11$)$ \\
\hline SSE intentions & 6.25 & 6.06 & $-0.19(-1.23$ to 0.86$)$ & 4.90 & 6.00 & $1.10(-1.44$ to 3.64$)$ & 5.29 & 6.13 & $0.84(0.42$ to 1.26$)$ \\
\hline $\mathrm{TCE}^{\mathrm{b}}$ intentions & $-^{c}$ & - & - & - & - & - & 6.02 & 6.58 & $0.56(0.18$ to 0.94$)$ \\
\hline Tanning norms & 3.95 & 3.48 & $-0.48(-1.00$ to 0.05$)$ & 4.52 & 4.28 & $-0.24(-1.05$ to 0.57$)$ & 3.73 & 3.76 & $0.02(-0.22$ to 0.27$)$ \\
\hline Sun protection norms & 3.98 & 3.48 & $-0.50(-0.94$ to -0.06$)$ & 3.29 & 3.77 & $0.49(-0.72$ to 1.69$)$ & 3.79 & 3.70 & $-0.08(-0.31$ to 0.15$)$ \\
\hline Image norms & 3.44 & 3.33 & $-0.12(-0.81$ to 0.57$)$ & 3.36 & 3.64 & $0.28(-0.52$ to 1.08$)$ & 3.66 & 3.53 & $-0.13(-0.36$ to 0.10$)$ \\
\hline
\end{tabular}

${ }^{\mathrm{a}} \mathrm{SSE}$ : skin self-examination.

${ }^{\mathrm{b}}$ TCE: total cutaneous examination.

${ }^{\mathrm{c}}$ The measure was not included for that Facebook group.

\section{Discussion}

\section{Principal Findings}

To the best of our knowledge, this is one of the first studies to evaluate a family-based skin cancer risk reduction intervention for young adults with melanoma and their relatives and the first behavioral intervention for this population delivered entirely through Facebook. Interventions delivered through social media are innovative and a promising way to reach young adults and their family members. In addition, Facebook provides a novel way to engage family members with one another, encourage young survivors to interact with other young survivors and their relatives, and facilitate engagement between families in learning and discussion about skin cancer. During the year-long development of the Facebook group methodology and its content, our team learned several lessons.
First, group engagement, as defined by participation (ie, likes and comments to original posts), improved steadily over the groups (eg, $0 \%$ of group 1 members and $9 \%$ of group 2 members commented on at least $25 \%$ of posts compared with $40 \%$ of group 5 members). Several factors may have contributed to this increase. A higher number of group members were recruited into each group over time, which may have increased the likelihood that one or more participants would post comments, find commonalities, and promote discussion. Another factor that may have increased participation was the quality of the posts. Based on the postgroup debriefing with participants and team discussion, we created posts that were briefer and designed to elicit interaction (eg, posed a question). Posts such as personal stories, goal-setting exercises, quizzes, and the opportunity to have questions answered by a cutaneous oncologist were rated as particularly engaging by group members.

The second lesson learned was that recruitment was challenging. Patient provision of relatives' contact information, reaching out 
to and enrolling relatives, completion of surveys, and ultimate acceptance into the Facebook group represent different steps with the potential loss of participants associated with each step. The most common point for participant loss was at the initial patient contact. Acceptance rates among patients differed by recruitment source, with a lower acceptance rate from the cancer center recruitment (at CINJ) than from the NJSCR. Family members joined the Facebook groups at higher rates than did patients. It is possible that recruitment from the cancer center provides the advantage of patient trust on the oncologist and knowledge of the institution. However, registry recruitment has the advantage of provision of greater reach into the general patient population. Another challenge was the relatively small number of relatives provided by each patient. One possible explanation is that patients stated they did not have siblings, suggesting smaller family size to be a reason.

The third lesson learned was that despite the challenges of enrollment, once enrolled, engagement was high, particularly in the latter groups. In their comments, participants shared their personal experiences with melanoma, provided each other with encouragement to undergo SSE and TCE and to engage in sun protection, asked one another for advice about sun protection products and recommendations for dermatologists who could perform exams, discussed personal barriers to sun protection and skin exams, set skin exam and sun protection goals, and posed questions for the cutaneous oncologist about melanoma and skin exams. Negative, off-topic, or unhelpful comments were not observed, although some members stated in their debriefing interviews that they did not share as much as they might have to not upset the family member who was diagnosed with cancer.

The fourth lesson learned was that evaluations of the groups, other than group 1, were positive. Participants reported that the content was informative and valid, the group prepared them to discuss skin cancer prevention with their family, and they felt comfortable sharing their experiences and connected with other group members. Given one of the key goals of this intervention was to encourage family members to support one another's skin cancer risk reduction, the fact that participants reported that the posts prompted discussions with their family members and that the group facilitated interactions with family members who were not participating in the group was encouraging.
Owing to the small sample size and the fact that outcomes were reported separately by group, it is difficult to make firm conclusions about the efficacy of the intervention. Our preliminary data suggest that there were increases in sun protection, SSE, and TCE intentions for the final 2 groups. There were generally inconsistent results with regard to improvements in the knowledge and beliefs outcomes. Definitive conclusions with regard to the efficacy of the intervention will require larger randomized clinical trials.

\section{Limitations}

Limitations of this study include low recruitment rates for patients and the small sample size. Future research is warranted to examine patients' and their family members' preferences with regard to delivery platforms for skin cancer prevention and surveillance interventions. Additionally, efforts are needed to identify strategies for maximizing participant recruitment, engagement, and retention for interventions delivered via social media and other platforms. The fact that we conducted 5 separate Facebook groups allowed the team to develop and refine the intervention in a deliberate, iterative manner based on participant engagement and feedback, which was the primary purpose of this study. The sample size in this study meant that we were not able to conduct a factor analysis of the Facebook group evaluation survey items. This should be addressed in future studies with larger sample sizes.

\section{Conclusions}

This pilot and feasibility study demonstrated that a moderated family-focused Facebook intervention for young-onset melanoma survivors and their family members is feasible and acceptable. For future similar research, we recommend Facebook group durations of at least 1 month with $\geq 35$ participants and regular posts by moderators. Because recruitment of patients was challenging, future studies may benefit from focusing on methods of enhancing patient recruitment. Additionally, although this study provided preliminary evidence of positive changes in outcomes, particularly with regard to behavioral intentions, further research is needed with larger sample sizes to determine the statistical and practical significance of such effects and to examine behavioral outcomes.

\section{Acknowledgments}

This research was supported by institutional funds to SLM, PhD. We thank Antoinette Stroup, PhD; Lisa Paddock, PhD; and other employees of the NJSCR for their valuable help in conducting this study and Evangelynn Murphy and Sara Frederick for assistance with data collection and management.

\section{Conflicts of Interest}

None declared.

\section{Multimedia Appendix 1}

Study survey measures. 


\section{Multimedia Appendix 2}

Engagement characteristics of the Facebook groups.

[PDF File (Adobe PDF File), 25KB-Multimedia Appendix 2]

\section{References}

1. Reed KB, Brewer JD, Lohse CM, Bringe KE, Pruitt CN, Gibson LE. Increasing incidence of melanoma among young adults: an epidemiological study in Olmsted County, Minnesota. Mayo Clin Proc 2012 Apr;87(4):328-334 [REE Full text] [doi: 10.1016/j.mayocp.2012.01.010] [Medline: 22469345]

2. Skin Cancer Foundation (SCF). Types of Melanoma URL: https://www.skincancer.org/skin-cancer-information/melanoma/ types-of-melanoma [accessed 2018-04-24] [WebCite Cache ID 6yv5umVZn]

3. Olsen CM, Carroll HJ, Whiteman DC. Familial melanoma: a meta-analysis and estimates of attributable fraction. Cancer Epidemiol Biomarkers Prev 2010 Jan;19(1):65-73 [FREE Full text] [doi: 10.1158/1055-9965.EPI-09-0928] [Medline: 20056624]

4. Frank C, Fallah M, Ji J, Sundquist J, Hemminki K. The population impact of familial cancer, a major cause of cancer. Int J Cancer 2014 Apr 15;134(8):1899-1906 [FREE Full text] [doi: 10.1002/ijc.28510] [Medline: 24590453]

5. Fears TR, Bird CC, Guerry D, Sagebiel RW, Gail MH, Elder DE, et al. Average midrange ultraviolet radiation flux and time outdoors predict melanoma risk. Cancer Res 2002 Jul 15;62(14):3992-3996 [FREE Full text] [Medline: 12124332]

6. Swerdlow AJ, Weinstock MA. Do tanning lamps cause melanoma? An epidemiologic assessment. J Am Acad Dermatol 1998 Jan;38(1):89-98. [Medline: 9448211]

7. Evans RD, Kopf AW, Lew RA, Rigel DS, Bart RS, Friedman RJ, et al. Risk factors for the development of malignant melanoma--I: Review of case-control studies. J Dermatol Surg Oncol 1988 Apr;14(4):393-408. [Medline: $\underline{3280634]}$

8. Aitken JF, Elwood M, Baade PD, Youl P, English D. Clinical whole-body skin examination reduces the incidence of thick melanomas. Int J Cancer 2010 Jan 15;126(2):450-458 [FREE Full text] [doi: 10.1002/ijc.24747] [Medline: 19609948]

9. Margolis MJ, De Champlain AF, Klass DJ. Setting examination-level standards for a performance-based assessment of physicians' clinical skills. Acad Med 1998 Oct;73(10 Suppl):S114-S116. [Medline: 9795671]

10. Berwick M, Begg CB, Fine JA, Roush GC, Barnhill RL. Screening for cutaneous melanoma by skin self-examination. J Natl Cancer Inst 1996 Jan 3;88(1):17-23 [FREE Full text] [Medline: $\underline{8847720}$ ]

11. Hamidi R, Cockburn MG, Peng DH. Prevalence and predictors of skin self-examination: prospects for melanoma prevention and early detection. Int J Dermatol 2008 Oct;47(10):993-1003. [doi: 10.1111/j.1365-4632.2008.03780.x] [Medline: 18986343]

12. American Cancer Society (ACS). Cancer Prevention \& Early Detection Facts \& Figures 2015-2016 URL: https://www. cancer.org/content/dam/cancer-org/research/cancer-facts-and-statistics/ cancer-prevention-and-early-detection-facts-and-figures/cancer-prevention-and-early-detection-facts-and-figures-2015-2016. pdf [accessed 2018-04-24] [WebCite Cache ID 6yv7NUqCJ]

13. Azzarello LM, Jacobsen PB. Factors influencing participation in cutaneous screening among individuals with a family history of melanoma. J Am Acad Dermatol 2007 Mar;56(3):398-406. [doi: 10.1016/j.jaad.2006.10.024] [Medline: 17184873]

14. Geller AC, Rutsch L, Kenausis K, Selzer P, Zhang Z. Can an hour or two of sun protection education keep the sunburn away? Evaluation of the Environmental Protection Agency's Sunwise School Program. Environ Health 2003 Nov 03;2(1):13 [FREE Full text] [doi: 10.1186/1476-069X-2-13] [Medline: 14613488]

15. Manne S, Fasanella N, Connors J, Floyd B, Wang H, Lessin S. Sun protection and skin surveillance practices among relatives of patients with malignant melanoma: prevalence and predictors. Prev Med 2004 Jul;39(1):36-47. [doi: 10.1016/j.ypmed.2004.02.028] [Medline: 15207984]

16. Friedman LC, Bruce S, Webb JA, Weinberg AD, Cooper HP. Skin self-examination in a population at increased risk for skin cancer. Am J Prev Med 1993;9(6):359-364. [Medline: $\underline{\text { 8311985] }}$

17. Lee JS, DuBois SG, Coccia PF, Bleyer A, Olin RL, Goldsby RE. Increased risk of second malignant neoplasms in adolescents and young adults with cancer. Cancer 2016 Jan 01;122(1):116-123 [FREE Full text] [doi: 10.1002/cncr.29685] [Medline: 26441212]

18. Bichakjian CK, Halpern AC, Johnson TM, Foote HA, Grichnik JM, Swetter SM, American Academy of Dermatology. Guidelines of care for the management of primary cutaneous melanoma. American Academy of Dermatology. J Am Acad Dermatol 2011 Nov;65(5):1032-1047. [doi: 10.1016/j.jaad.2011.04.031] [Medline: 21868127]

19. National Comprehensive Cancer Network (NCCN). Guidelines for patients: Melanoma URL: https://www.nccn.org/patients/ guidelines/melanoma/files/assets/common/downloads/files/melanoma.pdf[WebCite Cache ID 6yvO42lFQ]

20. Bowen DJ, Hay JL, Harris-Wai JN, Meischke H, Burke W. All in the family? Communication of cancer survivors with their families. Fam Cancer 2017 Oct;16(4):597-603. [doi: 10.1007/s10689-017-9987-8] [Medline: 28374161]

21. Rodríguez VM, Berwick M, Hay JL. Communication about melanoma and risk reduction after melanoma diagnosis. Psychooncology 2017 Dec;26(12):2142-2148. [doi: 10.1002/pon.4315] [Medline: 27862570]

22. Palesh O, Aldridge-Gerry A, Bugos K, Pickham D, Chen JJ, Greco R, et al. Health behaviors and needs of melanoma survivors. Support Care Cancer 2014 Nov;22(11):2973-2980. [doi: 10.1007/s00520-014-2286-0] [Medline: 24879390] 
23. Coups EJ, Manne SL, Stapleton JL, Tatum KL, Goydos JS. Skin self-examination behaviors among individuals diagnosed with melanoma. Melanoma Res 2016 Feb;26(1):71-76. [doi: 10.1097/CMR.0000000000000204] [Medline: 26426762]

24. Manne S, Lessin S. Prevalence and correlates of sun protection and skin self-examination practices among cutaneous malignant melanoma survivors. J Behav Med 2006 Oct;29(5):419-434. [doi: 10.1007/s10865-006-9064-5] [Medline: $\underline{16855870]}$

25. Geller AC, Dickerman BA, Taber JM, Dwyer LA, Hartman AM, Perna FM. Skin cancer interventions across the cancer control continuum: A review of experimental evidence (1/1/2000-6/30/2015) and future research directions. Prev Med 2018 Jun;111:442-450. [doi: 10.1016/j.ypmed.2018.01.018] [Medline: 29425724]

26. Wu YP, Aspinwall LG, Conn BM, Stump T, Grahmann B, Leachman SA. A systematic review of interventions to improve adherence to melanoma preventive behaviors for individuals at elevated risk. Prev Med 2016 Dec;88:153-167 [FREE Full text] [doi: 10.1016/j.ypmed.2016.04.010] [Medline: 27090434]

27. Bowen DJ, Burke W, Hay JL, Meischke H, Harris JN. Effects of web-based intervention on risk reduction behaviors in melanoma survivors. J Cancer Surviv 2015 Jun;9(2):279-286 [FREE Full text] [doi: 10.1007/s11764-014-0412-0] [Medline: 25425205]

28. Robinson JK, Turrisi R, Stapleton J. Efficacy of a partner assistance intervention designed to increase skin self-examination performance. Arch Dermatol 2007 Jan;143(1):37-41. [doi: 10.1001/archderm.143.1.37] [Medline: 17224540]

29. Pew Research Center. Social Media Update 2016: Facebook usage and engagement is on the rise, while adoption of other platforms holds steady URL: http://assets.pewresearch.org/wp-content/uploads/sites/14/2016/11/10132827/PI 2016.11. 11_Social-Media-Update_FINAL.pdf [accessed 2018-04-24] [WebCite Cache ID 6yvOUfUba]

30. Bruce A, Theeke L, Mallow J. A state of the science on influential factors related to sun protective behaviors to prevent skin cancer in adults. International Journal of Nursing Sciences 2017 Jul;4(3):225-235. [doi: 10.1016/j.ijnss.2017.05.005]

31. Pagoto SL, Baker K, Griffith J, Oleski JL, Palumbo A, Walkosz BJ, et al. Engaging Moms on Teen Indoor Tanning Through Social Media: Protocol of a Randomized Controlled Trial. JMIR Res Protoc 2016 Nov 29;5(4):e228 [FREE Full text] [doi: 10.2196/resprot.6624] [Medline: 27899339]

32. Naslund JA, Kim SJ, Aschbrenner KA, McCulloch LJ, Brunette MF, Dallery J, et al. Systematic review of social media interventions for smoking cessation. Addict Behav 2017 Oct;73:81-93. [doi: 10.1016/j.addbeh.2017.05.002] [Medline: 28499259]

33. Joseph RP, Keller C, Adams MA, Ainsworth BE. Print versus a culturally-relevant Facebook and text message delivered intervention to promote physical activity in African American women: a randomized pilot trial. BMC Womens Health 2015;15:30 [FREE Full text] [doi: 10.1186/s12905-015-0186-1] [Medline: 25886945]

34. Wójcicki TR, Grigsby-Toussaint D, Hillman CH, Huhman M, McAuley E. Promoting Physical Activity in Low-Active Adolescents via Facebook: A Pilot Randomized Controlled Trial to Test Feasibility. JMIR Res Protoc 2014;3(4):e56 [FREE Full text] [doi: 10.2196/resprot.3013] [Medline: 25357008]

35. Napolitano MA, Hayes S, Bennett GG, Ives AK, Foster GD. Using Facebook and text messaging to deliver a weight loss program to college students. Obesity (Silver Spring) 2013 Jan;21(1):25-31. [doi: 10.1002/oby.20232] [Medline: 23505165]

36. Cavallo DN, Tate DF, Ward DS, DeVellis RF, Thayer LM, Ammerman AS. Social support for physical activity-role of Facebook with and without structured intervention. Transl Behav Med 2014 Dec;4(4):346-354 [FREE Full text] [doi: 10.1007/s13142-014-0269-9] [Medline: 25584083]

37. Love C, Sabiston CM. Exploring the links between physical activity and posttraumatic growth in young adult cancer survivors. Psychooncology 2011 Mar;20(3):278-286. [doi: 10.1002/pon.1733] [Medline: 20238374]

38. Tai E, Buchanan N, Townsend J, Fairley T, Moore A, Richardson LC. Health status of adolescent and young adult cancer survivors. Cancer 2012 Oct 1;118(19):4884-4891 [FREE Full text] [doi: 10.1002/cncr.27445] [Medline: 22688896]

39. Manne SL, Coups EJ, Kashy DA. Relationship factors and couples' engagement in sun protection. Health Educ Res 2016 Aug;31(4):542-554. [doi: 10.1093/her/cyw027] [Medline: 27247330]

40. Glanz K, Lew RA, Song V, Murakami-Akatsuka L. Skin cancer prevention in outdoor recreation settings: effects of the Hawaii SunSmart Program. Eff Clin Pract 2000;3(2):53-61. [Medline: 10915324]

41. Jackson KM, Aiken LS. A psychosocial model of sun protection and sunbathing in young women: the impact of health beliefs, attitudes, norms, and self-efficacy for sun protection. Health Psychol 2000 Sep;19(5):469-478. [Medline: 11007155]

42. Manne SL, Meropol NJ, Weinberg DS, Vig H, Ali-Khan CZ, Manning C, et al. Facilitating informed decisions regarding microsatellite instability testing among high-risk individuals diagnosed with colorectal cancer. J Clin Oncol 2010 Mar 10;28(8):1366-1372 [FREE Full text] [doi: 10.1200/JCO.2009.25.0399] [Medline: 20142594]

43. Brug J, Conner M, Harré N, Kremers S, McKellar S, Whitelaw S. The Transtheoretical Model and stages of change: a critique: observations by five commentators on the paper by Adams, J. and White, M. (2004) why don't stage-based activity promotion interventions work? Health Educ Res 2005 Apr;20(2):244-258. [doi: 10.1093/her/cyh005] [Medline: 15618324]

44. Manne SL, Ostroff JS, Winkel G, Fox K, Grana G, Miller E, et al. Couple-focused group intervention for women with early stage breast cancer. J Consult Clin Psychol 2005 Aug;73(4):634-646. [doi: 10.1037/0022-006X.73.4.634] [Medline: $\underline{16173851]}$

45. Myers RE, Ross E, Jepson C, Wolf T, Balshem A, Millner L, et al. Modeling adherence to colorectal cancer screening. Prev Med 1994 Mar;23(2):142-151. [doi: 10.1006/pmed.1994.1020] [Medline: $\underline{\text { 8047519] }}$ 
46. Real K, Rimal RN. Friends talk to friends about drinking: exploring the role of peer communication in the theory of normative social behavior. Health Commun 2007;22(2):169-180. [doi: 10.1080/10410230701454254] [Medline: 17668996]

47. Rimal RN, Lapinski MK, Cook RJ, Real K. Moving toward a theory of normative influences: how perceived benefits and similarity moderate the impact of descriptive norms on behaviors. J Health Commun 2005;10(5):433-450. [doi: 10.1080/10810730591009880] [Medline: 16199387]
Abbreviations
CINJ: Cancer Institute of New Jersey
NJSCR: New Jersey State Cancer Registry
SSE: skin self-exam
TCE: total cutaneous exam

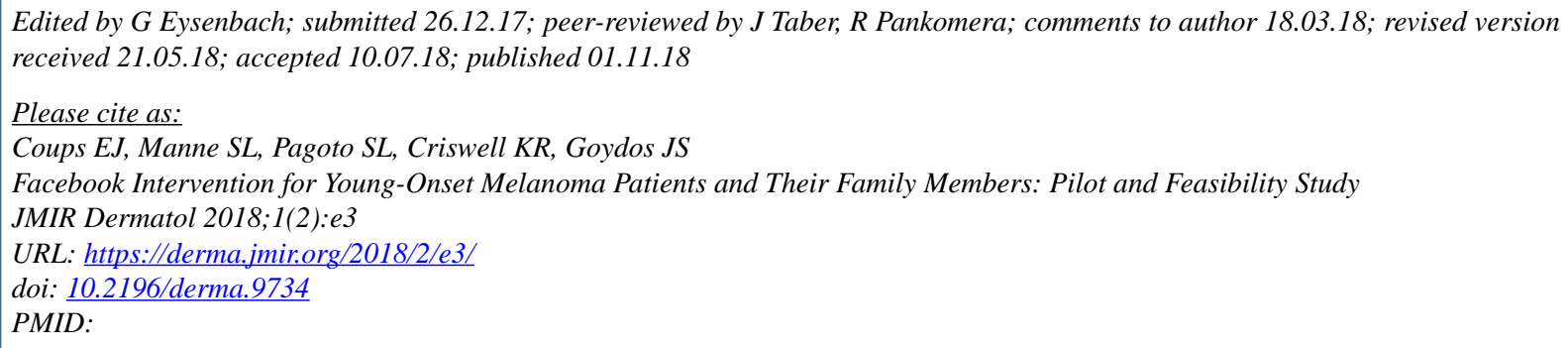

CElliot J Coups, Sharon L Manne, Sherry L Pagoto, Kevin R Criswell, James S Goydos. Originally published in JMIR Dermatology (http://derma.jmir.org), 01.11.2018. This is an open-access article distributed under the terms of the Creative Commons Attribution License (https://creativecommons.org/licenses/by/4.0/), which permits unrestricted use, distribution, and reproduction in any medium, provided the original work, first published in JMIR Dermatology Research, is properly cited. The complete bibliographic information, a link to the original publication on http://derma.jmir.org, as well as this copyright and license information must be included. 